This item was submitted to Loughborough's Research Repository by the author.

Items in Figshare are protected by copyright, with all rights reserved, unless otherwise indicated.

\title{
Stress in youth sport: a developmental investigation of tennis parents
}

PLEASE CITE THE PUBLISHED VERSION

http://dx.doi.org/10.1016/j.psychsport.2009.01.005

PUBLISHER

(c) Elsevier

VERSION

AM (Accepted Manuscript)

LICENCE

CC BY-NC-ND 4.0

REPOSITORY RECORD

Harwood, Chris G., and Camilla J. Knight. 2019. "Stress in Youth Sport: A Developmental Investigation of Tennis Parents". figshare. https://hdl.handle.net/2134/15212. 
This item was submitted to Loughborough's Institutional Repository (https://dspace.lboro.ac.uk/) by the author and is made available under the following Creative Commons Licence conditions.

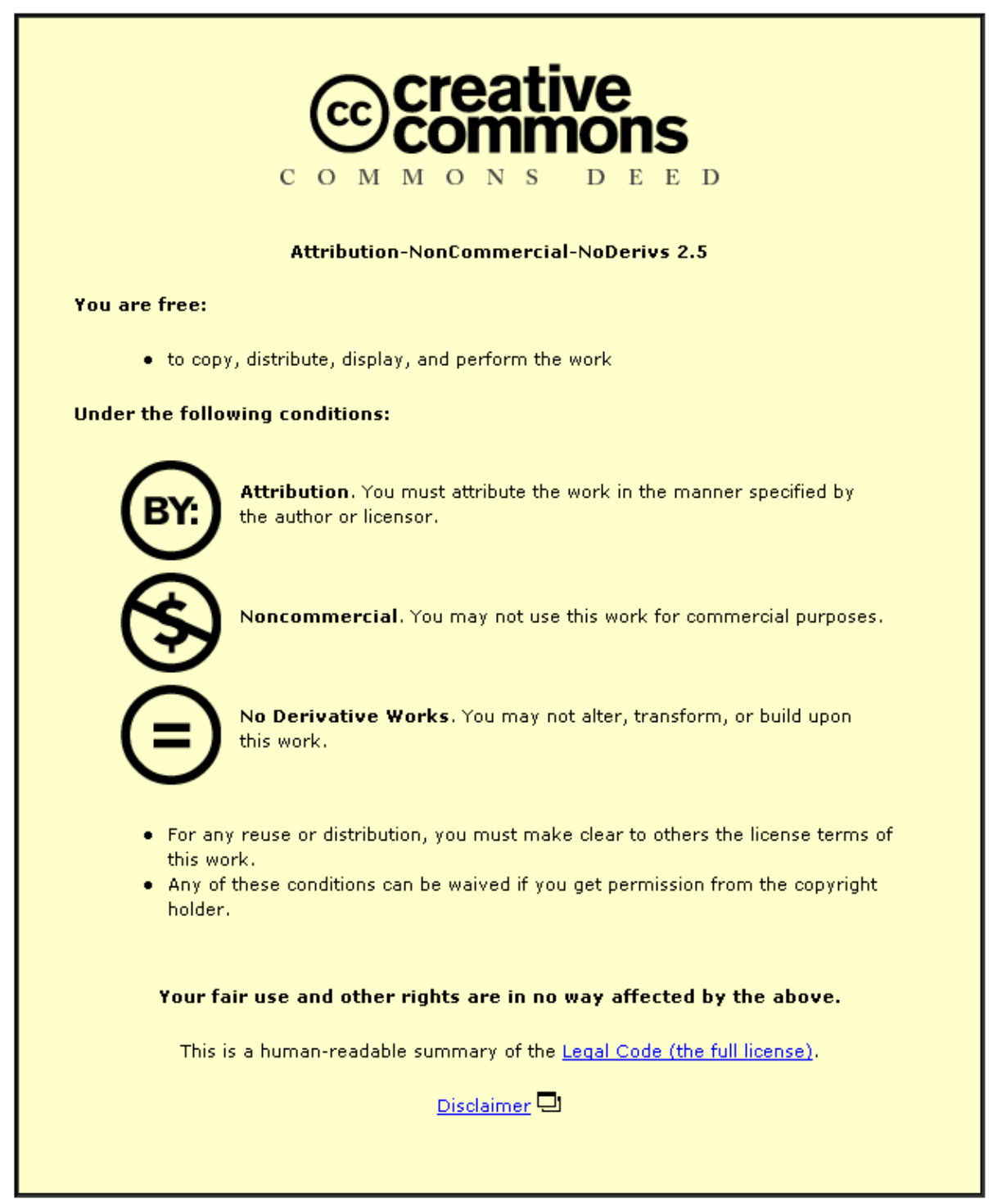

For the full text of this licence, please go to: http://creativecommons.org/licenses/by-nc-nd/2.5/ 


\section{Accepted Manuscript}

Title: Stress in youth sport: A developmental investigation of tennis parents

Authors: Chris Harwood, Camilla Knight

PII: $\quad$ S1469-0292(09)00008-9

DOI: $\quad$ 10.1016/j.psychsport.2009.01.005

Reference: $\quad$ PSYSPO 391

To appear in: Psychology of Sport \& Exercise

Received Date: 2 June 2008

Revised Date: 21 January 2009

Accepted Date: 24 January 2009

Please cite this article as: Harwood, C., Knight, C. Stress in youth sport: A developmental investigation of tennis parents, Psychology of Sport \& Exercise (2009), doi: 10.1016/j.psychsport.2009.01.005

This is a PDF file of an unedited manuscript that has been accepted for publication. As a service to our customers we are providing this early version of the manuscript. The manuscript will undergo copyediting, typesetting, and review of the resulting proof before it is published in its final form. Please note that during the production process errors may be discovered which could affect the content, and all legal disclaimers that apply to the journal pertain. 
Stress in youth sport: A developmental investigation of tennis parents

Chris Harwood and Camilla Knight, Loughborough University, UK

Date of Revision: 3/11/08

Running Head: PARENTAL STRESS IN YOUTH SPORT

All correspondence may be addressed to:

Dr. Chris Harwood, Sport and Exercise Psychology Research Group, School of Sport and Exercise Sciences

Loughborough University, Loughborough

Leics Tel: 01509226342

LE112DHＣ.g.harwood@lboro.ac.uk 
Parental stress in youth sport 1

1

\section{Objective}

3

4

5 of participation in the sport (Côté, 1999).

6

7

8

9

Key words: parent, tennis, stress, developmental, youth sport

Abstract Design and method of the data between themes.

Results and conclusion

This study investigated the stage-specific stressors experienced by British tennis parents whose children were situated either in the sampling, specializing or investment stages

A qualitative design was employed with semi-structured interviews conducted with twenty two British tennis parents; six parents representing each of the first two stages of sports participation and ten representing the investment stage. Data was analyzed through a process of inductive content analysis following the method proposed by Miles and Huberman (1994). Data matrices were developed for each category of parent to allow for the comparison

Three general dimensions of parental stressor emerged: Organizational, Competitive and Developmental. Organizational stressors included demands related to finance, time, training and coaching, and governing body systems; competitive stressors related to behavior, performance and morality-related issues associated with their child’s matches; and developmental stressors centered on educational issues, uncertainty of tennis transitions, and future decision making. While sampling stage parents encountered few developmental stressors compared to later stage parents, a range of competitive stressors were highly prominent. Organizational stressors were particularly foremost for specializing and investment stage parents. Implications are discussed with reference to further research into the parental stress process and to the importance of stage-specific parent education initiatives. 
Parental stress in youth sport 2

Stress in youth sport: A developmental investigation of tennis parents

By the very nature of its participants, research into the domain of competitive youth sport focuses as much on the influential roles and behaviors of coaches, parents and peers as it does on the experiences and responses of the young athlete (e.g. Côtè \& Hay, 2002). For example, when we consider the social psychological research on sport-parents, they are often portrayed in a more negative than positive light and through the lens of coaches and athletes' reported perceptions (see DeFrancesco \& Johnson, 1997; Gould, Lauer, Rolo, Jannes, \& Pennisi, 2006, 2008; Hellstedt, 1990; Leff \& Hoyle, 1995). Youth tennis is one sport subculture that tends to attract this research attention due to problematic parental behavior that is frequently reported in the media (see Lichfield, 2006). However, very few studies have investigated parental perceptions and experiences of youth sport from the parents’ own perspectives (Holt, Tamminen, Black, Sehn \& Wall, 2008).

The recent prosecution of Christophe Fauviau, the father of two French teenage players found guilty of manslaughter after drugging his son's opponent, offers a reminder of the sometimes irrational human investment that parents may place in their child's sporting development. However, at a more rational level, it speaks to the taxing nature of youth sport and the stressors experienced by parents within their sport-parent roles (Hellstedt, 1987; Lazarus, 2006). Unfortunately, whilst the study of personal, competition, and organizational stressors faced by athletes and coaches has a well-developed literature base (e.g., Hanton, Fletcher \& Coughlan, 2005; Giacobbi, Foore \& Weinberg, 2004; Gould, Eklund \& Jackson, 1993; Holt \& Hogg, 2002; Thelwell, Greenlees \& Hutchings, 2008; Woodman \& Hardy, 2001), limited attention has been afforded to the range of stressors experienced by parents as they support their child through their stages of sport development (Côtè, 1999). Therein lies the precise focus for this current investigation. 
Parental stress in youth sport 3

1

2

Parents play a critical role in children's socialization to sport and throughout their sporting lives (Brustad, 1996; Wuerth, Lee \& Alfermann, 2004). Fredricks and Eccles (2004) noted that parents fulfill three fundamental roles in their child's sport experience. These are firstly as ‘provider’ (e.g., of opportunities, finance, transport); as ‘interpreter’ of the sport experience for their child (e.g., emotionally reacting to competition in adaptive manners); and finally, as 'role model' (i.e., modeling the ideal attributes and behaviors in sport). The extent to which these roles are fulfilled by parents influences a child's beliefs and values and in turn, their motivated behaviors and performance.

Nevertheless, the extensive emotional, financial, and logistical support that parents prioritize for their children (see Baxter-Jones \& Maffuli, 2003; Kirk et al., 1997a; Kirk et al., 1997b; Wolfenden \& Holt, 2005) may come at a cost with respect to the stress that they experience. Indeed, like Fauviau, the negative influence and impact of parents often reported by coaches and athletes anecdotally, and in youth sport research, is potentially related to stressors that they experience in their parental roles.

In establishing a line of research into stress from a parental perspective, Harwood and Knight (in press) investigated the stressors articulated by 123 British tennis parents. The wide range of stressors emerging from their open-ended survey coalesced into seven core themes of parental stress. These included stressors associated with attendance at matches and tournaments; coaches behaviors and responsibilities, financial and time demands placed upon the family; sibling resentment and unequal attention; inefficiencies and inequalities attributed to tennis organizations; and developmental concerns related to educational and future tennis transitions. Whilst this study provided a much needed insight into the scope of stressors experienced in the sport-parent role, it lacked an in-depth understanding of how such stressors may differ depending upon a child’s stage of development (Côtè, 1999). Such insights would provide practitioners, coaches, and governing body organizations with a deeper, evidence- 
Parental stress in youth sport 4

1 based appreciation of the main issues and needs of parents across the key transitional stages

2 of their child's sport participation.

A number of researchers have identified stages that athletes pass through during their

4 sports career or involvement (e.g., Balyi, 2000; Bloom, 1985; Wylleman \& Lavallee, 2004).

5 Côtè's (1999) stages of sport participation model is frequently adopted because it is sport

6 specific and sensitive to the developmental transitions children experience (Wolfenden \&

7 Holt, 2005). Within the context of this study, Côtè's model is of interest because it focuses on

8 the first eighteen years of an athlete's development, when parental requirements are likely to

9 be at their greatest.

Côtè (1999) identified four stages of participation: sampling, specializing, investment, and recreation; the first three of which are relevant to the current study. His model traces sport participation from early childhood to late adolescence and identifies differences in the experiences and requirements of athletes during each stage. The role and requirements of parents have also been noted to change throughout these stages (see Côtè, 1999; Côtè \& Hay, 2002; Wolfenden \& Holt, 2005).

In the sampling years, families play a central role in the athlete's development. Family time is devoted to a number of activities, but much time is devoted to sport. Parents play clear 'provider' roles and are responsible for initiating sports activities and ensuring transportation and access (Durand-Bush, Salmela \& Thomson, 2004). Parents are required to be highly committed to their child's sport, displayed through altered family routines as well as emotional and financial support (Wolfenden \& Holt, 2005). During this stage, however, fun is of utmost importance to athletes, emphasizing deliberate play rather than intense training

23 (Côtè \& Hay, 2002).

24 During the specializing stage, sport-specific skills develop through practice, with a reduction in deliberate play (Côtè \& Hay, 2002). Parents take a growing interest in their child 
Parental stress in youth sport 5

1 Bush et al., 2004). The time commitment is such that other opportunities are often sacrificed

2 for a child's sport. Furthermore, there is a premium placed on a parent's nurturing role

3 alongside the provision of moral and socio-emotional support (Wolfenden \& Holt, 2005;

4 Wuerth et al., 2004).

5 Finally, athletes reach the investment years. At this stage the child pursues the aim of

6 reaching an elite level in their chosen sport. Children increase the intensity of their

7 commitment to one sport and there is a substantial increase in deliberate practice (Côtè \&

8 Hay, 2002). Parents' levels of support and interest in their child-athlete may result in them

9 displaying different treatment toward their other children (Durand-Bush et al., 2004; Wuerth

10 et al., 2004). Nevertheless, during this stage, parents’ actual requirements may begin to

11 decrease as coaches play a larger role.

12 Considering the differing emotional, financial, and logistical requirements of parents,

13 the experiences of athletes, and the changing competition and training demands associated

14 with each stage of development, it is conceivable that parental stressors may also vary.

15 Therefore, in extending the work of Harwood and Knight (in press), the purpose of this study

16 was to conduct an in-depth, comparative examination of the stressors perceived by tennis

17 parents whose children were located within one of the three stages of sport participation

18 (Côtè, 1999). The investigation formed part of a research initiative supported by Great

19 Britain’s tennis governing body, the Lawn Tennis Association (LTA). The overall aim was to

20 develop a clearer understanding of stage-specific parental stressors so that appropriate

21 resources and support would enable parents towards positive role-related influences on their

22 children's talent development in the sport. 
Parental stress in youth sport 6

1

\section{Participants} programs. Procedure
Method

The sample comprised 22 tennis parents: Nine mothers, five fathers, and four sets of parents who were interviewed together. The sample was divided into three groups: six parents of performance juniors, six parents of top county/low national standard players, and ten parents of national and international (academy) standard players. The performance juniors (three boys and two girls) were aged between 9 and 11 and were classified as being in the sampling stage. The second category accounted for parents of four boys and two girls aged from 11 to 16 and considered as being in the specializing stage. The final group comprised parents of academy players, aged 12 to 16 . These players trained at national tennis academies and fulfilled the characteristics of athletes in the investment stage. Six players resided full time at the academies and two commuted daily, with all players on modified educational closely as possible and occurred through discussion with the players’ parents and coaches. These discussions revolved around (a) the current focus of training sessions (deliberate play or deliberate practice), (b) players involvement in other sports, and (c) the emphasis placed upon general motor skill development compared to tennis-specific skills training.

A purposive sampling strategy highlighted 25 tennis parents who were available and interested in engaging in this study. These parents were identified through discussions with county officials, coaches, and clubs. Three parents subsequently withdrew from the study due to personal commitments and scheduling problems. Semi-structured interviews were deemed the most appropriate method of data collection for this study because they allow in-depth information to be gained from participants discussing their interpretation of the tennis experience and expressing 
Parental stress in youth sport 7

1 situations from their own point of view (Cohen, Manion \& Morrison, 2001; Denzin \&

2 Lincoln, 2005). This was particularly important in the study considering the subjective

3 and individual nature of stress. (Lazarus, 2006).

4 Data collection

5 A semi-structured interview guide was developed based upon results of an open-

6 ended survey of British tennis parents (Harwood \& Knight, in press), the requirements of

7 sports parents, and potentially stressful areas highlighted in past research (e.g., Kirk et al.,

8 1997a, 1997b; Wolfenden \& Holt, 2005). Care was taken by the interviewer not to lead

9 participants' responses by commencing with introductory questions about the parents'

10 general experiences of stress in tennis. Using the nature and depth of these initial

11 responses, the guide allowed the interviewer to probe these responses in more detail

12 assisted by broad areas of interest that could be covered according to the varying flow of

13 the interview. These included: matches and competitions; coaching and training; finances;

14 national governing body and other organizations; personal, social, and family life; and

15 education and transitions. Therefore, as opposed to asking specific, structured (and

16 potentially confirmatory) questions, the interviewer used these broad areas to probe a

17 parent's response further or to assist in the recollection of their contextual experiences.

18 Further, a final comments section was also important in picking up any additional

19 stressors that parents felt that they had not articulated. This section was important given

20 that parent(s), by this stage in the interview, had become fully immersed in the topic.

21 All interviews were conducted by a female interviewer, who was also a qualified

22 professional coach with a high level of tennis playing experience. This served to facilitate the

23 development of rapport with the participants and a closeness to the phenomena under

24 investigation. Prior to carrying out the interviews, two pilot interviews were completed with

25 parents of a sampling stage and a specializing stage junior. These lasted 45 and 52 minutes

26 respectively and were taped and reviewed with the co-author. Both pilot interviews allowed 
1 the interviewer to rehearse and refine the interview procedure, including the efficient use of

2 elaboration and clarification probes. The pilot process subsequently reduced the potential for

3 interviews to deviate through the course of study and to increase the trustworthiness of the

4 results (Miles \& Huberman, 1994; Johnson, 1997).

5 Before each interview the participants were provided with a written and verbal

6 introduction. The introduction outlined the research, reassured confidentiality, and also

7 included definitions of stress and stressors (Lazarus, 2006). Participants were reminded that

8 they were free to discuss any issues they felt were relevant to the topic. Informed consent was

9 obtained and any questions were answered. Both parents in the tennis family were initially

10 approached and where parents were interviewed together about their experiences, questions

11 were directed separately to each parent to enable disclosure of their own individual and

12 personal perceptions. This assisted the interviewer in gaining independent perceptions of

stressors. Where interviews involved only the dominant/most involved parent, this was

deemed satisfactory given that they were likely to be the parent of greatest interest and

relevance. The interviews lasted between 22 and 87 minutes $(M=54.0$ mins).

Data Analysis

Each interview was taped and transcribed verbatim immediately following its completion. Pseudonyms were assigned to each participant to ensure confidentiality throughout the analysis process. The interviews were read and reread to ensure that the researcher was fully immersed in the transcripts. Data was then analyzed through a process of inductive content analysis following the method proposed by Miles and Huberman (1994). Raw data meaning units were identified that represented the core stressors reported by parents. Each meaning unit was then coded into a first order thematic category or essence phrase that essentially represented a cluster of similar stressors (Maykut \& Morehouse, 1994). This analytical process then progressed inductively to a higher thematic level (i.e., higher 
Parental stress in youth sport 9

1 of parental stress. To facilitate the comparative analysis of stage-specific parental stress,

2 meaning units and themes were identified for each participant individually, within each

3 category of parents, and in the overall sample. Data matrices (Miles \& Huberman, 1994) were

4 developed for each category of parents to allow for the comparison of the data between

5 themes. In sum, the percentage of parents within each stage that articulated stressors within

6 each sub-theme and subsequent higher order theme provided evidence of the similarities and

7 differences between parents' experiences across the three stages.

8 Methodological Rigor

A number of steps were introduced to enhance the trustworthiness of the findings, and their credibility and dependability in particular (Johnson, 1997). Firstly, engaging in pilot interviews (and maintaining the same interviewer throughout) helped to maximize interview consistency as well as encouraging a prolonged engagement with the parent population. The experience of the interviewer as a player and coach also encouraged an affinity with this subculture. Secondly, an audit trail was consistently maintained of the analytical decisions and processes stemming from the raw data meaning units to the final interpretive dimensions. This process also aided the researcher's reflexivity in forcing them to reflect on decisions made with an eye to their personal assumptions or biases about the topic. Thirdly, all interview transcripts and a summary of the results were returned to participants for member checking and participant feedback (Cohen et al., 2001; Johnson, 1997). This allowed participants to confirm whether the transcripts and results provided an accurate and valid reflection of their experiences. Furthermore, they were provided with the opportunity to further substantiate their experiences or provide additional information. All participants confirmed their transcripts and validated the thematic frameworks. Two parents further reinforced key points that had emerged through the data analysis. Finally, and importantly, investigator triangulation was achieved with the first author reading all of the transcripts and then independently identifying the raw data units for one 
Parental stress in youth sport 10

1 third of the parent sample from each category. This process led to a 90\% agreement rate with

2 the second author's raw data interpretations. Following discussion and consensus at this stage,

3 the first author checked the interpretive allocation of the raw data into the first order sub-

4 themes and the labeling applied to each theme. This process of inductive verification between

5 the two authors continued until the final general dimensions were agreed and the percentages

6 of parents citing stressors in each stage of development were intact and verifiable.

7

Results

Analysis of the interviews led to the identification of three general dimensions of parental stressors: Organizational, Competitive, and Developmental (see Tables 1, 2 and 3). These general dimensions included 18 higher order themes, 62 sub-themes, and 253 raw data themes. This section will explore each general dimension and higher order theme across the three stages. Quotes will be utilized to illustrate examples of raw data and sub-themes with keys denoting the stage of development (i.e., Sa= Sampling; Sp=Specializing; In=Investment) alongside whether it was a mother $(\mathrm{M})$ or father $(\mathrm{F})$ and their participant number in that stage (e.g., SpM3). The table for each general dimension illustrates the percentage of parents in that stage who cited stressors within each sub-theme and higher order theme.

\section{General dimension one: Organizational stressors}

Six higher order themes, 27 sub-themes and 137 raw data themes emerged in relation to organizational stressors rendering it as the most diverse dimension in the study. This dimension was characterized by stressors that parents perceived in relation to the logistical environment, personal investments and tennis systems within which they themselves operate (see Table 1).

Time emerged as a prominent stressor for all participants. The day-to-day time requirements and organization required to enable participation and progression in tennis impacted upon a parent's general lifestyle, family routines and obligations. One mother recounted: 
Parental stress in youth sport 11

I think probably you get so tired sometimes when you are just doing all the traveling, all the training, running a home, and all the other stuff with other members of the family as well on top of everything else ...you feel a bit stressed out then. (InM5)

Furthermore, as one father stated, “That is my life: work, tennis, bed!” (SaF1). Parents with other children described feelings of guilt and worry in response to the stressors that arise because of the unequal time they spend with one child compared to other siblings. As one mother said, "You know at some point you will be reminded that you've spent 10 weekends in a row going to one child's tournaments” (InM8).

Whilst all sampling stage parents cited varying time stressors, work and social role conflicts alongside tennis administration tasks were particularly prevalent in specializing stage parents. These issues continued into the investment stage. However, parents in this stage whose children lived away from home at tennis academies acknowledged that whilst time stressors still existed relating to tournaments, the day-to-day time requirements were less. As one mother stated “I don’t feel I have [stress] now because she’s away on a day to day basis” (InM5).

$$
\text { Many parents in the specializing and investment stages recalled extensive financial }
$$
stressors. Parents in the sampling stage estimated costs between $£ 2,000$ and $£ 3,500$ a year on tennis with one parent expressing stressors regarding future financial costs of tennis involvement: "I mean if he was to go to Newquay and win the area tournament they'd say “right, next week Leeds”... I’m pretty sure we wouldn’t be able to do that” (SaF3). However, in the specializing and investment stage the burden appeared to increase enormously. As one mother stated, "It just spirals out of control” (InM3). Parents with children in the investment stage estimated spending between $£ 15,000$ and $£ 20,000$ per year on tennis. One family declared, “We have been broke for eight years and that's no exaggeration” (InF1). Another mother divulged, “I’ve already re-mortgaged twice and I’m thinking I might have to do it again” (InM6). 
Parental stress in youth sport 12

1 Due to the financial demands of tennis, specializing and investment stage parents often

2 sought to obtain sponsorship, with related stressors experienced in contrasting ways. The

3 following quotes highlight two examples: a) "It is very, very difficult with sponsorship

4 because most companies do not want to sponsor individuals they want to sponsor teams”

5 (InM6); b) “I run sponsorship deals... So I personally have additional stressors that some of

6 the other parents don't have to endure... I have a commitment obviously to the sponsors in

7 terms of what they want back out of the deal” (SpF1).

Allocation of funding was pertinent to parents with players in the latter stages and was one of many stressors parents expressed in relation to the National and County Tennis Associations. All investment stage parents perceived the lack of transparency of funding as a stressor. As one mother highlighted, “It's not transparent so you're not sure whether... you're getting your correct allocation of funding support” (InM4). Consequently, stressors relating to perceived favoritism emerged:

It used to be very unequal, how they would deal with players, offering opportunities around... You could see that a group of four, right at the top, would get everything and that little trailing group [would get nothing]. It wasn't spread widely enough across (InM3).

The most substantial stressor that parents recounted, across all three stages, in relation to the governing body was a lack of information, support and guidance. Parents with children in the sampling and specializing stages were unaware of the best course of action to help their child progress. As one mother highlighted, “There are people in positions [of power] that oversee who could say, '[your child] shouldn’t be there now, move on'. But they're not prepared to do that openly” (SpM1). The lack of information and guidance also led to stressors arising in the investment stage, as one father explained, "International tournaments abroad are quite stressful in getting those organized. There’s not enough help really from the LTA in that respect” (InF3). 
Parental stress in youth sport 13

1 Beyond the lack of information, parents across each stage professed a received

2 lack of respect from the national/county associations and coaches. This promoted both

3 frustration and ill-feeling, as the following quote summarizes:

4 You don't get informed. They [national coaches] look at you, you know, you

5 send your child off on these [national training] camps somewhere and when you say “Can you give me some feedback?”... “What you - the parent?!, What right have you got to know? Oh no no no, we'll tell the coach. (SpF1) Stressors perceived to be associated with the national governing body were not limited to funding, information, and coaches. However these were far more frequently recalled than other issues. Two further organizational themes that arose related to injury and tournaments, both with increasing frequency in the specializing and investment stage. The impact of injury on playing form and lack of support provided for injured players was highlighted as a stressor by a number of investment parents, as the following quote highlights: physio and do it all ourselves. The LTA then requested he played in a tournament,

Furthermore, injury and health gradually became longer-term concerns for parents compared

to the absence of such issues in sampling stage. One mother recounted: She went through a phase when she had a lot of injuries and that does worry me for the long term. I think they have wonderfully healthy heart and lungs, but I do worry about their joints, they are going to suffer when they are older. (SpM4) 
Parental stress in youth sport 14

1 problems for many parents in the specializing and investment stages. As one mother

2 explained:

3 Bournemouth in August, let's face it, that is the most crazy place to go for something

$4 \quad$ like the Nationals when you may not even know that you are going [to be accepted into

5 the draw] right until the last minute. (InM6)

6 Later stage parents were also aggravated by the altered weekend tournament structure and the

7 subsequent impact this has on accommodation and finance amongst other aspects:

If you don't win on the first day you go home. When we go away we stay at Travel Inn's and Travelodge's. They used to have a cancellation policy where you could cancel up to 4pm. But now it's 1pm! Well, you've often not even gone on court for your second match by then so you could pay hundreds of pounds on accommodation... and then the rooms aren't used. (InM4)

General dimension two: Competitive stressors

Analysis of the interviews extracted 66 raw data themes that formed 24 sub-themes and eight higher order themes associated purely with a child's competitive matches (see Table 2). Firstly, a number of parents across all stages cited the stress of logistical and preparatory issues prior to the match, and particularly the psychological readiness and focus of their child. Some parents noted the difficulties of seeing their child nervous, feeling pressured or not focusing on the upcoming match in the way they thought was necessary. One parent stated: The major stress comes from my son playing matches and there's not a lot you can do about that. You need the coach to help him stop showing disappointment and stress because then it will be less stressful for me. (SaF1).

The majority of parents identified watching matches as a stressor, with many stating it was the largest stressor they encountered (e.g. “The biggest stress for me I suppose is actually watching her play” InM2). The child's performance, behavior, and the outcome of the match were inextricably linked to this. One parent identified, “It’s stressful as a parent because you 
Parental stress in youth sport 15

1 always want them [your child] to do well” (SpM2). Furthermore, parents wanted their child

2 to be happy, and parental stress was enhanced when they saw their child distressed on court,

3 displaying bad behavior, or expressing disappointment following a match. As one parent

4 noted, “That's the worst when you see them get upset and you can't do anything. (SaF3)”

5 The stress of being powerless to do anything to help their child was exacerbated when

6 they perceived their child to be performing below their ability. As one mother described, "It's

7 like watching them sit a maths exam isn't it... and watching them put all the wrong answers

8 in really” (InM5). Additionally, this feeling of helplessness occurred in parents when their

9 child suffered problems with their opponent. One father explained the predicament:

I've had two or three incidents where... we had one where you can only describe it as bullying, you know my child was being bullied...being threatened aggressively on court in front of me...your powerless as a parents...it's not my job to do anything. $(\mathrm{SpF} 1)$

Many aspects relating to opponents and other parents were expressed as stressors, with extensive examples being provided. Their child's opponent was perceived as a stressor due to their behavior, (poor) line calls, and gamesmanship. As one mother articulated, “There was a particular boy... who was very well renowned for his absolutely horrendous tactics which dogged us for a couple of years...in some ways it taught Matthew ${ }^{* 1}$ very valuable lessons. At other times, it was absolutely beyond the pale” (InM7). In relation to other parents, witnessing them putting pressure on their children was acknowledged by some parents as a stressor, as the following quote explores, "Parents can actually shock me because they get so angry with their children or so stressed out with their children” (SpF1). Additionally, a number of participants cited the stress and resulting embarrassment when they felt other parents were evaluating their child’s performance and behavior. As one parent highlighted, “I don’t want him to do it [throw his racquet] ... I think it’s bad behavior, other people see, and you become embarrassed” (InM6). 
Parental stress in youth sport 16

1 Competitive stressors were prevalent across all three stages of sport participation.

2 However, the majority of the higher order themes and underpinning sub-themes were

3 populated more prominently with sampling stage parents. Sub-themes associated with other

4 tennis parents, the child's behavior and performance, and the outcome of the match were

5 examples of this trend.

6

In general, stressors associated with other parents appeared to reduce across the three

7 stages with less threatening, interfering and intimidating behaviors observed by investment

8 stage parents. However, many of these parents still appeared to be affected by the perceived

9 gossip and back-biting culture of other parents in this later stage. Similarly, stressors

associated with the outcome of the match were more prominent in sampling parents. Nearly

11 all sampling parents discussed the stressors associated either with their child's reaction to a

loss, or not knowing exactly what to say or do. The following quote was expressed throughout

13 the sampling stage:

It's when you want to talk on the way home that gets stressful, that's the worst, the journey home after is the stressful part. If they've had a good day it's not a problem because they want to talk about everything they’ve done.... when they’ve had a bad day they don't want to talk about it and I don't know what to say. (SaF3) In the sampling stage, competitive stressors appeared to be enhanced due to the age of the children, as one father explained, "I think maybe [I need to have] experienced more of this ... I'm hoping that the younger age, because kids are still misbehaving and cheating and parents are interfering, [is more stressful]” (SaF2). Furthermore, parents appeared new to the situations and to the process of coping with the stressors they experience. All specializing and investment parents acknowledged that competitive stressors still existed, however, many explained that they used to be far worse. The following quote summarizes such sentiments, "I think things have changed. ... I think when you first start out and you think 'what's all this about?' and then you probably become more stressed, but then you deal with it [and] it 
Parental stress in youth sport 17

1 becomes less stressful perhaps” (SpF1). Similar thoughts were echoed by another parent who

2 stated, "I think when we first started I watched every point and was quite conscious of where

3 things were going. Now I try to be a little bit more laid back about it. (InM8)”

$4 \quad$ Nevertheless, in both the specializing and investment stage, a small number of parents

5 perceived competitive stressors to be greater than in the sampling stage because of the

6 increasing importance of match outcomes. One parent highlighted, “As kids tend to get better

7 the parents sort of become more involved and perhaps expectations get raised and it becomes

8 more stressful the better they get” (InF2). These feelings were reflected in sub-themes

9 related to poor line calls and opponent behavior, the child's maintenance of focus in

10 competition and performing to their full ability. All of these sub-themes remained elevated

11 and indicative of the clear impact and implications that they would have at this stage (e.g., on

12 international/academy selection; rankings).

\section{General dimension three: Developmental stressors}

Fifty raw data themes that coalesced into 11 sub-themes and four higher order themes represented parental experiences of stressors associated with their child's development (see Table 3). Few parents with children in the sampling stage reported any developmental stressors whatsoever. Parents indicated that this was due to their child's age and recent introduction and commitment to tennis. However, developmental stressors were highly prominent within parents in the specializing and investment stage; the most common of these being their child's education.

As one investment parent reinforced, “The decisions regarding education are huge” (InM4). Education appeared to be a greater stressor for those parents who perceived their child was academically able and who placed great value and importance on education for their child's future achievement. Issues regarding education were exacerbated for some parents due to conflict and a lack of support from their child's school. The following quote encapsulates such stressors: 
Parental stress in youth sport 18

I did fight very hard for them to understand that he needed to come out of school, he needed to miss lessons...the headmistress just didn't understand and the local authority who had to give permission...they didn’t understand either. (InM6)

Uncertainties around the child's future emerged as stressors for a majority of parents in the specializing stage. Many were unsure what their child wished to achieve in tennis, or were concerned that they had high aspirations that were unlikely to be fulfilled. As one parent commented, “He’s at a point now where I think he’s got to be realistic that he's probably not going to be making a living from it [tennis]... But I'm not brave enough to tell him that” (SpM1). Such thoughts were confirmed by another mother in the investment stage, who explained, “It does concern me because he has high hopes, and at the same time, you've got to be realistic because there are so few that make it” (InM6). A few investment stage parents perceived the future as their largest current and immediate stressor. One family explained such a situation:

“That is... at the moment... it’s becoming stressful because we'll know in the next month what is going to happen with Amy*. Whether they select her to go down to the National Tennis Centre or whatever. Because if she doesn't go, then she'll have to decide what she’s going to do. (InF1)

In comparison, other investment parents took a more carefree approach to the future, for example, one parent acknowledged, “Things will change, but we just take a little chunk at a time” (InM4).

The third theme that emerged relating to developmental stressors was making decisions necessary to enable their child's progression in tennis. Again, this was recalled only once in the sampling stage, with the parent acknowledging, "It's the not knowing what's around the corner and where to go next” (SaM1). In the specializing stage, this stressor appeared more often, as one parent described, “It’s more of a worry, am I doing the right thing for him? Is he with the right coach?” (SpM1). For parents of players in the investment 
Parental stress in youth sport 19

1 stage decision-making remained a worry and this was particularly evident in relation to

2 decisions to let children go to residential tennis academies. One mother recalled that making

3 the decision caused, “A week of sleepless nights” (InM5).

$4 \quad$ Over the later stages, a small number of parents acknowledged issues relating to other

5 sports or hobbies. Reasons for this stress included letting other people down or their child

6 missing out on other sports. In the sampling stage, most children were able to participate as

7 they wished in other sports without additional stress. As they progressed through the stages,

8 parents identified that other sports stopped. Nonetheless, because it was their child's decision,

9 few parents noted this as stressful.

\section{Discussion}

Stress is widely acknowledged as an inherent part of competitive sport and continues to receive extensive research attention amongst athletes and coaches (Giacobbi et al., 2004; Hanton et al., 2005; Thelwell et al., 2008). However, if the realm of youth sport seeks to optimize the role related performance and psychological well being of sport parents, then there is a premium placed on understanding the inherent stressors that may impact on the quality of their role with the child-athlete (see Gould et al., 2006, 2008).

The overall findings of the study served to corroborate the initial survey-based research of Harwood and Knight (in press). In their study, before, during, and after match stressors associated with their child's behavior, the opponent, other parents, and their own expectations were reported as foremost issues. Finance, time, family, and other organizational issues were also prominent, as were developmental concerns related to educational and future tennis transitions. However, the current results offered a closer appreciation of the key stressors as their child progresses from one stage of participation to the next.

The findings also conceptually support the distinction that researchers are now making between those stressors linked specifically to competition and competitive performance (i.e., competitive stress) with the stressors associated primarily and directly with the organization 
Parental stress in youth sport 20

1 within which the individual is operating (i.e., organizational stress; Hanton, et al., 2005;

2 Hanton \& Fletcher, 2005; Woodman \& Hardy, 2001). Such dimensions of stress apply to

3 sport-parent roles, and parents' experiences of stress in youth sport can be viewed through the

4 lens offered by Hanton and Fletcher’s (2005) conceptualization of organizational stress. By

5 adapting Cooper, Dewe and O’Driscoll's (2001) work in an organizational setting, Hanton

6 and Fletcher (2005) forwarded five dimensions of organizational stressor in sport: factors

7 intrinsic to the sport; roles in the sport organization; sport relationships and interpersonal

8 demands; organizational structure and climate of the sport; and athletic career and

9 performance development issues.

Factors intrinsic to the sport of tennis including stressors associated with time,

11 finances, travel, accommodation, training, injury and tournament schedules were particularly

12 prominent amongst specializing and investment stage parents (Kirk et al., 1997a; Wolfenden

13 \& Holt, 2005). The time commitment required from tennis parents has been identified to

14 increase as children moved from the sampling stage to the specializing stage and then

15 decrease as parents take a step back during the investment stage (Wolfenden \& Holt, 2005).

16 This pattern was largely supported in the current study. Parents in the specializing stage

17 experienced greater time and family-related stressors than those in the sampling stage due to

18 the increase in training and competition load. Investment parents with the highest standard

19 children who lived away from home at academies acknowledged reduced time stress

20 compared to their previous specializing phase because of the lesser 'everyday' burden of their

21 child's regime at home.

Specializing parents also tended to report greater sport-family role conflict where the role pressures of being an 'organised' tennis parent conflicted with other family activities and

24 responsibilities (Greenhaus \& Beutell, 1985). Yet it was clear that a number of these later stage parents felt a systematic lack of respect and communication from the national governing

26 body and coaches in terms of acknowledging their role in the organization of their child's 
Parental stress in youth sport 21

1 tennis experience. The vast majority of parents disclosed stressors associated with sport

2 relationships and interpersonal demands, mainly related to other tennis parents or to their own

3 child with respect to negative behaviors or dealing with the outcome of competitive matches.

4 Additionally, it was the specializing and investment parents who highlighted the greatest

5 stressors with respect to the organizational structure and climate of the sport. Issues related to

6 the transparency and equality of player funding, favoritism, tournament structures, injury

7 considerations, and the ratings system correlated with the increasing standard, time, and

8 investment that characterized the parent's and child's inputs and outputs.

Finally, the developmental stressors that emerged for parents in the present study were closely representative of longer term concerns linked to the athlete career and performance

11 development dimension of organizational stress (Hanton \& Fletcher, 2005). As Rotella and Bunker (1987) acknowledge, "Parents of children who make a serious commitment to sport face a difficult challenge: to raise a happy, healthy, and successful child” (p. 15). When parents reached the specializing stage (and beyond), they appeared to enter a phase of conflict, worry, and uncertainty around their child’s education, their tennis development and future prospects related to both domains. Sidebotham (2001) notes the stress experienced by parents in relation to their expectation for their children to achieve. For child-athletes such achievements may be in relation to both sporting and academic success, with parents needing information and support on the most appropriate decisions and pathways. Parents in the current sample worried about making incorrect decisions regarding their child's academic or tennis future and felt enormous pressure to follow either the academic or tennis route and hope that their child was successful in this. Parents with children in the sampling stage generally perceived that such decisions were not pertinent at this time, and consequently experienced far less developmental stress. It is also interesting to note that while some later stage parents did cite stressors associated with long term health and injury, few referred to 
Parental stress in youth sport 22

1 friendships that can often suffer through investments into one sport.

2 Whilst it was apparent through the interviews that parents in the latter two stages

3 encountered a greater range of organizational and developmental stressors, it was the

4 sampling stage parents who appeared particularly susceptible to the varying competitive

5 stressors. During the sampling stage, the focus is upon fun and deliberate play (Côtè \& Hay,

6 2002), with a limited emphasis upon competition. As such, one may anticipate that

7 competitive stressors are minimal during this stage. However, even at the earliest stages of

8 participation, tennis players are encouraged to engage in competitions to supplement their

9 training. Whilst tournaments for children at this stage are supposed to be relaxed and often

10 team-based affairs, there are several factors inherent to tennis that fuel emotions and negate

11 temperance. The scoring system immediately punishes individual mistakes and brutally

12 exposes the competence of players in a highly public and evaluative manner (see Harwood \&

13 Swain, 2001). Moreover, tennis is one of the few sports where young players officiate their

14

matches and are responsible for calling their own lines and keeping score. These competition demands offer many emotional challenges for young parents who essentially seek both a psychologically safe and fair environment for their child. Factors such as unsporting opponent behaviors, the evaluations, interference and intimidation of other parents, the performance and behavior of their own child, and their helplessness in being unable to intervene and assist were widely representative of this stage. In sum, it was clear through the interviews that many sampling parents found their initial and current experiences of watching tennis competitions to be highly stressful.

Not surprisingly, as some investment parents qualified, coping with these competitive demands comes with experience and there were some parents in these later stages who acknowledged better coping mechanisms with respect to some of these match-related stressors. Nevertheless, the specializing and investment stage are both associated with an increase in competition (Côtè \& Hay, 2002), and a number of parents indicated that they had 
Parental stress in youth sport 23

1 been unable to develop resources to cope with these stressors despite their past experience.

2 Indeed, the competitive stressors associated with watching matches, other parents' and

3 opponents' behaviors, and their child's attitude and behavior were generally consistent across

4 stages. There are many pertinent explanations for this.

5 Firstly, as athletes progress, the financial, time, and emotional investment from

6 parents and athletes themselves increases in parallel (cf. Gould et al., 2008; Wolfenden \&

7 Holt, 2005). Competitive matches carry more important and meaningful consequences;

8 positive behavioral expectations are greater for all concerned as is the demand for accuracy

9 and fairness in terms of line calling. Additionally, in the absence of coaches at tournaments, it

10 is parents who are the sole providers of preparation and support before, during, and after

11 matches. Independent of a child's age or standard, all parents identify with their children and

12 want them to be happy and successful (Rotella \& Bunker, 1987; Smoll, 2001). Consequently,

13 within this integral support role at competitions, any situation that may cause children distress

14 or disappointment is likely to be difficult and potentially stressful for parents. In addition,

15 Coakley (2006) observed that children's sporting excellence is often attributed to parents,

16 especially fathers and in this sample some parents disclosed the stress associated with

17 preserving their own public image and avoiding embarrassment through their child's on court

18 behavior (see Gould et al., 2008).

\section{Limitations, future directions and applied implications}

There are a number of limitations and future directions that are important to acknowledge in this study, as well as practical implications for sport psychologists, coaches, and governing body organizations. Firstly, the allocation of children (and thus parents) to stages was based on the characteristics of each stage (Côté, 1999), as opposed to a specified age range. Thus, the specializing and investment stage incorporated a wide range of ages, whereas the sampling stage included only children aged 9-11. Consequently, the stressors experienced by parents may have been affected by the age of the child in addition to their 
Parental stress in youth sport 24

1 stage of tennis participation. In addition, the use of interviews with parents who have been

2 through the full system, in combination with these stage-specific interviews may have

3 provided further credibility to the results as a form of method triangulation. This additional

4 data may have substantiated the subjective perceptions of parents at each stage and reinforced

5 the prevalence of certain stressors more commonly shared by parents at different time points.

6 However, it is fair to note that investment stage parents who had naturally 'lived through' the

7 other two stages validated the overall results and insights during their member check.

It is also appropriate to recognize that the study did not intentionally examine

9 psychological strain, or the methods of coping that parents employed to deal with the stressors

10 that they encountered (Lazarus, 2006). Whilst the interviews illustrated how some parents

11 lacked the resources to deal with particular stressors, and subsequently experienced negative

12 emotions, it would be worthwhile if future research paid closer attention to the full stress and

coping process in sport parents. A key extension of this research is to ascertain if and how

parental stressors (and parental coping) influence successful versus unsuccessful athlete

career development. In light of the current investigation, for example, does a parent who

experiences a range of competitive stressors have a sub-optimal impact on players in their

17 formative sampling years? Similarly, do parents who fail to manage certain organizational

and developmental stressors in the specializing and investment phases negatively influence

the decision-making and transitions of their child (Gould et al., 2008). Such studies would

continue to ameliorate the scientific knowledge base of the 'sport-parent' and enable parents

to be more effective in their roles as provider, interpreter and role-model (Fredricks \& Eccles,

\section{2004).}

Various practical implications can be drawn from this study that are of central importance to practitioners, coaches, parents, and sporting organizations. First, there is a need to educate and empathize with all parents in relation to the psychological and emotional 
Parental stress in youth sport 25

1 behavioral, and motivational skills both to manage themselves and to influence the responses

2 of their child (Gould et al., 2008; Harwood \& Knight, in press). This is a particularly

3 important initiative for sampling stage parents who are new to the sport and less aware of

4 those factors that can potentially make tennis an unpleasant early experience for child and

5 parent. The provision of materials or induction workshops at local tournaments for young

6 parents would facilitate this goal (see USTA, 2006). However, as competition frequency and

7 standards increase into the specializing and investment stages, this parent education should be

8 tailored towards the parent who experiences those stressors more associated with match

9 outcomes and expectations about their child's performance.

10 Secondly, stage-specific stressors are likely to be reduced if parents of talented

11 athletes possess an advanced awareness of the financial, time, family, and education-related

12 issues that they may face as their child progresses through the sport. Improved

13 communication, feedback and information from governing bodies might include guidance on

14 sponsorship and funding as well as preparatory information to assist parents in their decision

15 making about education, academies, and training program requirements. Some of this

16 responsibility should lie with their child's coach both in empathizing with family demands,

17 ensuring regular feedback, and advising parents with honesty and clarity on player

18 development options. Such initiatives are likely to enhance the roles, well-being, and stress

19 management of tennis parents and it is worth noting that the Lawn Tennis Association has

20 begun to disseminate this work throughout its organization and within its coaching

21 qualifications.

Conclusion

This study enabled parents to articulate the stressors that they experienced in their role as an integral supporter of their child's tennis development. While parents with children in the sampling stage encountered fewer overall stressors than those with children in the later two 
Parental stress in youth sport 26

1 stages, competitive stressors were highly prominent. Specializing stage parents shared the

2 most stressors, presenting united perceptions of organizational issues such as finance and

3 time, as well as developmental concerns surrounding education and future decision making.

4 Many of these competitive, organizational and developmental stressors remained for parents

5 in the investment stage. However, with greater experience of matches and tournaments, and

6 children residing away from home, some of these stressors were reduced. The findings

7 highlight the importance of not only supporting the roles of the sport-parent, but empathizing

8 with their demands and needs in terms of their effective execution of such roles. In this

9 respect, we may begin to optimize a child's sport experience and development in conjunction

10 with the work of coaches and governing body organizations. 
Parental stress in youth sport 27

1

2 Balyi, I. (2000). Sport system building and long term athlete development in British

References
4

5

6

7

Columbia. Canada: SportsMed BC. Retrieved January 2006, from:

http://www.sportdevelopment.org.uk/balyibc2001.pdf

Baxter-Jones, A.D., \& Maffuli, N. (2003). Parental influence on sport participation in elite

young athletes. The Journal of Sports Medicine and Physical Fitness, 43, 250-255.

Bloom, B. (1985). Developing talent in young people. New York: Ballantine Books.

Brustad, R.J. (1996). Parental and peer influence on children’s psychological development

through sport. In F.L. Smoll, \& R.E. Smith (Eds.), Children and youth in sport: A

0 biopsychosocial perpective (pp.112-124). Madison, WI: Brown and Benchmark.

Coakley, J. (2006). The good father: Parental expectations and youth sport. Leisure Studies, 2 25, 153-163.

Cohen, L., Manion, L., \& Morrison, K. (2001). Research methods in education (5 ${ }^{\text {th }}$ ed.). London: Routledge.

Cooper, C. L., Dewe, P. J., and O’Driscoll, M. P. (2001). Organizational stress: A review and critique of theory, research, and applications. Thousand Oaks, CA: Sage.

Côtè, J. (1999). The influence of the family in the development of talent in sport. The Sport Psychologist, 13, 395- 417.

Côtè, J., \& Hay, J. (2002). Children’s involvement in sport: A developmental perspective. In J.M. Silva, \& D.E. Stevens (Eds.), Psychological foundations of sport (pp. 484-502). 1 Boston, MA: Allyn and Bacon.

22 Denzin., N.K., \& Lincoln., Y.S. (2005). The SAGE handbook of qualitative research (3 ${ }^{\text {rd }}$ Edition). Sage: London.

4 DeFrancesco, C., \& Johnson, P. (1997). Athlete and parent perception in junior tennis. 5 Journal of Sport Behavior, 20, 29-36. 
Parental stress in youth sport 28

1 Durand-Bush, N., Salmela, J.H., \& Thompson, K.A. (2004). Le role joue' par les parents dans

2 le developpement et le maintien de la performance athletique experte. STAPS, 64, 15-38.

3 Fredricks, J.A., \& Eccles, J.S. (2004). Parental influences on youth involvement in sports. In

$4 \quad$ M.R.Weiss (Ed.), Developmental sport and exercise psychology: A lifespan perspective.

5 (pp. 145-164). Morgantown, WV: Fitness Information Technology.

6 Giacobbi, P., Foore, B. \& Weinberg, R. (2004). Broken clubs and expletives: The sources of

$7 \quad$ stress and coping responses of skilled and moderately skilled golfers. Journal of applied

8 sport psychology, 16, 166-182.

9 Gould, D., Eklund, R.C., \& Jackson, S.A. (1993). Coping strategies used by US Olympic

$10 \quad$ wrestlers. Research Quarterly for Exercise and Sport, 64, 453-468.

11 Gould, D., Lauer, L., Rolo, C., Jannes, C., \& Pennisi, N. (2006). Understanding the role

12 parents play in tennis success: a national survey of junior tennis coaches. British Journal of

$13 \quad$ Sports Medicine, 40, 632-636.

14 Gould, D., Lauer, L., Rolo, C., Jannes, C., \& Pennisi, N. (2008). The role of parents in tennis

15 success: Focus group interviews with junior coaches. The Sport Psychologist. 22, 18-37.

16 Greenhaus, J. H., \& Beutell, N. J. (1985). Sources of conflict between work and family roles.

17 Academy of Management Review, 10, 76-88.

18 Hanton, S., \& Fletcher, D. (2005). Organizational stress in competitive sport: More than we

19 bargained for? International Journal of Sport Psychology, 36, 273-283.

20 Hanton, S., Fletcher, D., \& Coughlan, G. (2005). Stress in elite sport performers: A 21 comparative study of competitive and organizational stressors. Journal of Sports Sciences, $22 \quad 23,1129-1141$.

23 Harwood, C.G., \& Knight, C.J. (in press). Understanding parental stress: An investigation of 24 British tennis parents. Journal of Sport Sciences.

Hellstedt, J.C. (1987). The parent/coach/athlete relationship. The Sport Psychologist, 1, 15126 160. 
Parental stress in youth sport 29

1 Hellstedt, J.C. (1990). Early adolescent perceptions of parental pressure in the sport

2 environment. Journal of Sport Behavior, 13, 135-144.

3 Holt, N.L., \& Hogg, J.M. (2002). Perceptions of stress and coping during preparations for the 41999 women’s soccer world cup finals. The Sport Psychologist, 16, 251-271.

5 Holt, N.L., Tamminen, K.A., Black, D.E., Sehn, Z.L., \& Wall, M.P. (2008). Parental

6 involvement in competitive youth sport settings. Psychology of Sport \& Exercise, 9, 663-

$7 \quad 685$.

8 Johnson, B. R. (1997). Examining the validity structure of qualitative research. Education, $9 \quad 118,282-292$.

10 Kirk, D., Carlson, T., O’Connor, A., Burke, P., Davis, K., \& Glover, S. (1997a). The

11 economic impact on families of children's participation in junior sport. Australian Journal 12 of Science and Medicine in Sport, 29, 27-33.

13 Kirk, D., O’Connor, A., Carlson, T., Burke, P., Davis, K., \& Glover, S. (1997b). Time

14 commitments in junior sport: Social consequences for participants and their families.

15 European Journal of Physical Education, 2, 51-73.

16 Lazarus, R.S., (2006). Stress and Emotion: A new synthesis. New York: Springer.

17 Leff, S.S., \& Hoyle, R.H. (1995). Young athlete’s perceptions of parental support and 18 pressure. Journal of Youth and Adolescence, 24, 187-203.

19 Lichfield, J. (2006, March 10). Obsessive father jailed for tennis player's death. The 20 Independent, p. 22.

21 Maykut, P., \& Morehouse, R. (1994). Beginning qualitative research: A philosophic and 22 practical guide. Lewes, UK: Falmer.

23 Miles, M.B., \& Huberman, A. M. (1994). Qualitative data analysis. London: Sage.

24 Rotella, R.J., \& Bunker, L.K. (1987). Parenting your superstar. Champaign, IL: Human $25 \quad$ Kinetics. 
Parental stress in youth sport 30

1 Sidebotham, P. (2001). Culture, stress and the parent-child relationship: A qualitative study of

2 parents' perceptions of parenting. Child: Care, Health and Development, 27, 1-18.

3 Thelwell, R. C., Weston, N. J. V., Greenless, I. A., \& Hutchings, N. V. (2008). Stressors in

4 elite sport: A coach perspective. Journal of Sports Sciences, 26, 905-918.

5 USTA (2006). Recommended guidelines for successful junior tennis parenting.

6 Available:www.playerdevelopment.usta.com/content/fullstory.sps?iNewsid=146001\&ityp

$7 \quad$ e=7417. Retrieved: March, $10^{\text {th }}, 2008$.

8 Wolfenden, L.E., \& Holt, N.L. (2005). Talent development in elite junior tennis: Perceptions

9 of players, parents and coaches. Journal of Applied Sport Psychology, 17, 108-126.

10 Woodman, T., \& Hardy, L. (2001). A case study of organizational stress in elite sport.

11 Journal of Applied Sport Psychology, 13, 207-238.

12 Wuerth, S., Lee, M.J., \& Alfermann, D. (2004). Parental involvement and athletes' career in 13 youth sport. Psychology of Sport and Exercise, 5, 21-33.

Wylleman, P., \& Lavallee, D. (2004). A developmental perspective on transitions faced by athletes. In M.R.Weiss (Ed.), Developmental sport and exercise psychology: A lifespan perspective (pp. 503-524). Morgantown, WV: Fitness Information Technology, Inc.

$*^{1}$ denotes that a pseudonym has been used

* Whilst $100 \%$ of investment parents recognized these stressors, they perceived them to be reduced compared to their experience of the specializing stage.

Acknowledgements:

24 This research was supported by the Lawn Tennis Association of Great Britain and we would 25 like to acknowledge the support of staff at the National Tennis Centre. London. 
Parental stress in youth sport 1

Table 1

A comparative analysis of organizational stressors reported by parents across the sampling, specializing and investment years

Higher Order Theme

Sampling Specializing Investment \%

Subthemes

Time

Impact on social life

Work-Tennis role conflict

Organization and administration of tennis

Lack of sibling attention including sibling resentment

Lack of family and partner time

$100 \quad 100 \quad 100 *$

Finances

Sponsorship organisation and commitments

Lack of player funding

Financial impact on family and siblings

Financial decisions around coaching and tournaments

67

50

50
33

33

\section{3}

83

100

90

67

83

60

50

83

83

80

100

50

Organizing bodies (national /county and club)

\section{0}

\section{0}

50

33

\section{7}

17

100

67

$67 \quad 100$

Lack of information, feedback and guidance

Pressures of the player ratings system

Support and respect from the British tennis system

Transparency and equality of funding

67

$67 \quad 100 \quad 90$

$\begin{array}{lll}33 & 83 & 50\end{array}$

$\begin{array}{lll}50 & 67 & 70\end{array}$

$0 \quad 50 \quad 100$

Tournaments

$83 \quad 100$

100

Tournament structures, draw and seedings

Inefficient tournament organization

17

83

Travelling to matches

Accommodation issues and decisions

Geographical location and selection

Training and Coaching

100

\section{7}

\section{3}

67

33

33

50

40

90

30

100

Feedback, respect and commitment of coaches

Quality and scheduling of training programme

Problems associated with academy programmes

Access to training facilities

$\begin{array}{ccc}67 & 50 & 80 \\ 50 & 50 & 70 \\ 0 & 0 & 70 \\ 0 & 50 & 40\end{array}$

Injury

$\begin{array}{lll}0 \quad 83 & 100\end{array}$

Insufficient advice and support

Loss of play impact on form, skills and rating

Long term impact on tennis and health

Costs of treatment and rehabilitation

Process and penalties of match withdrawal

$\begin{array}{lcc}0 & 33 & 60 \\ 0 & 67 & 90 \\ 0 & 33 & 40 \\ 0 & 17 & 0 \\ 0 & 17 & 0\end{array}$


Parental stress in youth sport 2

Table 2

A comparative analysis of competitive stressors reported by parents across the sampling, specializing and investment years

Higher Order Theme

Sampling Specializing Investment \%

Subthemes

Watching matches

Avoiding placing pressure on child

Helplessness to deal with 'during-match' issues

Wanting child to succeed/win

Other tennis parents

Seeing parents pressurizing their child

Threatening behavior due to result

Gossip, back biting and cliqueyness

Interfering and intimidation during match

Child's behavior and attitude

Bad line calls and cheating

Bad physical and verbal behavior

Player distress and lack of coping

Child's opponent

Bad line calls and cheating

Bullying, swearing and gamesmanship

Preparation for matches

Sufficiency and quality of training

Logistical arrangements

Physical and dietary readiness

Child’s performance

Performing to their full ability

Inconsistency of play and momentum changes

Level of child's effort

Outcome of the match

The child's reaction to the match

Talking/consoling child following defeat

Dealing with negative behavior (by either player)

Child’s psychological readiness

Child's nervousness before matches

Pressure/expectations that child places on themselves

Child maintaining focus during the match
67

83

80

50

50

67

50

60

67

67

70

70

100

83

80

$50 \quad 33 \quad 30$

67

67

83

50

83

67

30

70

30

100

83

100

$50 \quad 33 \quad 50$

67

83

67

50

60

50

67

83

100

67

67

80

67

60

67

67

60

33

50

50

50

50

50

30

50

40

67

50

50

50

33

50

50

50

50

33

40

10

83

67

60

67

67

50

33

33

40

50

67

50

30

30

50

33

70

33

50

20

40

$\begin{array}{lll}50 & 33 & 60\end{array}$


Parental stress in youth sport 3

Table 3

A comparative analysis of developmental stressors reported by parents across the sampling, specializing and investment years

Higher Order Theme

Sampling Specializing Investment \%

Subthemes

Child's education

Value placed on academic achievement

Coaches beliefs in tennis over education

Managing conflicts with school

Child's future

Uncertainties of the future within tennis Knowledge of what opportunities are available

Uncertainty of impact on child's general life

Making appropriate decisions regarding tennis

Selection of correct coach for progression

Tournament-related decisions

Amounts/type of training specific to individual child

Impact on other hobbies

Child missing out on other sports

Letting other people down
0

83

83

17

33

17

83

83

17

0

0

17

17

33

83

67

67

$\begin{array}{ll}0 & 67 \\ 17 & 33\end{array}$

90

90

10

40

50

0

50

20

$0 \quad 50$

20

0 